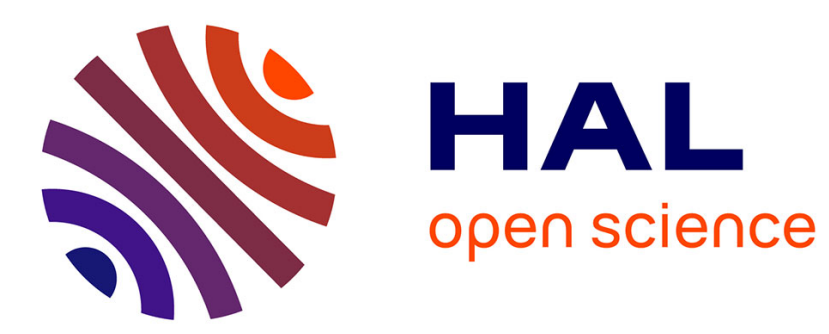

\title{
Dynamic Local Strain Measurement From the Digital Image Processing of the Grating Interrogation
}

\author{
V. Vallé, M. Cottron, A. Lagarde
}

\section{To cite this version:}

V. Vallé, M. Cottron, A. Lagarde. Dynamic Local Strain Measurement From the Digital Image Processing of the Grating Interrogation. Journal de Physique IV Proceedings, 1997, 07 (C3), pp.C3193-C3-198. 10.1051/jp4:1997335 . jpa-00255492

\section{HAL Id: jpa-00255492 https://hal.science/jpa-00255492}

Submitted on 1 Jan 1997

HAL is a multi-disciplinary open access archive for the deposit and dissemination of scientific research documents, whether they are published or not. The documents may come from teaching and research institutions in France or abroad, or from public or private research centers.
L'archive ouverte pluridisciplinaire HAL, est destinée au dépôt et à la diffusion de documents scientifiques de niveau recherche, publiés ou non, émanant des établissements d'enseignement et de recherche français ou étrangers, des laboratoires publics ou privés. 


\title{
Dynamic Local Strain Measurement From the Digital Image Processing of the Grating Interrogation
}

\author{
V. Vallé, M. Cottron and A. Lagarde \\ LMS, SP2MI, Bd 3, Téléport 2, BP. 179, 86960 Futuroscope cedex, France
}

\begin{abstract}
The direct measurement of local strains during a dynamic loading is proposed from the spectral analysis of a crossed grating using optical diffraction under oblique incidence This procedure is experimentally achieved with acousto-optic modulators which allow to record 24 strain states at a maximum frequency near to $1 \mathrm{MHz}$. The diffraction figures can be recorded on a photographic film or directly on a C.C.D. camera. The automatic localisation of the diffracted spots with the help of data image processing gives the components of the strain tensor. The strain measurement method is performed for compression impact tests using an Hopkinson bar loading.
\end{abstract}

Résumé. La mesure directe des déformations en dynamique met à profit l'analyse spectrale de réseaux croisés par diffraction sous incidence oblique. La mise en oeuvre expérimentale utilise des modulateurs acousto-optiques qui permettent l'enregistrement de 24 états de déformation à une fréquence maximum proche du $\mathrm{MHz}$. Les figures de diffraction sont enregistrées sur plan film ou directement sur camera C.C.D.. La localisation automatique des taches diffractées au moyen d'une procédure de traitement et d'analyse d'images fournit les composantes du tenseur des déformations. La métrologie développée est appliquée sur des essais d'impact en compression par barres d'Hopkinson.

\section{INTRODUCTION}

Among the experimental methods, the optical measurement methods occupy an increasing place due to the properties of the light laser sources and to the easiness of the analysis using image processing techniques. The optical methods, which allow non-contact and non disturbing evaluations, are well adapted to investigate dynamic events. With the use of high speed recording systems, we can have access to stresses from photoelasticity or caustic method, to displacements from holography or moiré interferometry. The purpose of our contribution concerns the direct measurement of local strains during a dynamic loading from the spectral analysis of a crossed grating.

The grating method [1] allows to determine the magnitude and the orientation of the principal strain as well as the rigid body rotation. This is obtained from [2] the comparison between the geometry of a deformed crossed grating (pitch and orientation of each direction of grating) with the geonetry of the same grating in the initial state. The analysis of the grating is achieved for static investigutions by an optical Fourier transform or a numerical one [3] [4]. This method is performed for the measurement of small and large strains in static regime with a strain sensitivity [5] comparable to the one obtained by strain gauge

Investigations of dynamic problems from grating analysis have been performed [6] few decades a aso. The complexity of the used procedure has induced to give up utilising this technique. The propused method, which takes advantage of the modern experimental tools, is based on the spectral analysis of at crossed grating using the optical diffraction phenomenon under oblique incidence. The performintes af the developed method are demonstrated for the local strain measurement method during a dunamic loading. 


\section{PRINCIPLE}

The grating interrogation is performed using optical diffraction of the grating with a variable oblique incidence. By associating with each strain state a specific angle of the incident laser beam, we can separate the diffracted beams during the dynamic event in order to give easier the optical data analysis. We have so to take account of the diffraction phenomenon in oblique incidence. This phenomenon is presented (Figure 1) for an uni-directional grating analysed on reflection by a laser beam.

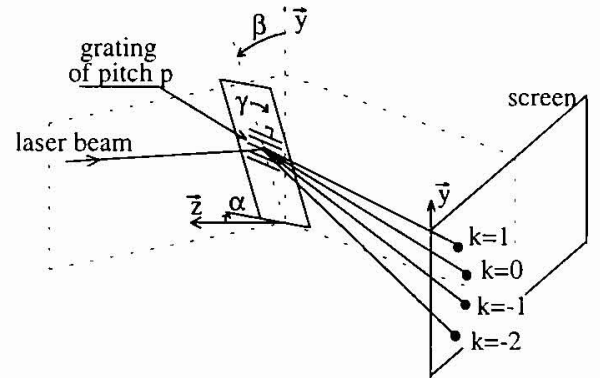

Figure 1: Oblique diffraction phenomenon

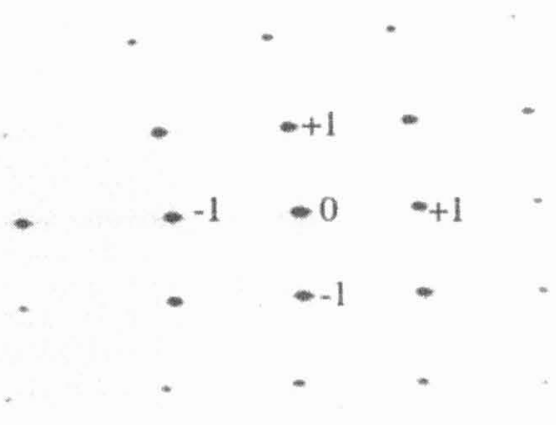

Figure 2: Oblique diffraction of a crossed grating

We give (Figure 2) the diffraction spots issued from a crossed grating. It is necessary to record the 0 order for the determination of the orientation of the measurement base and the diffracted orders +1 associated with the two grating families for the measurement of the strain components. The analysis of these 5 diffracted spots is performed by solving [7] a system of 15 equations with 14 unknowns. The comparison of these 14 unknowns with the quantities at initial state gives the components of the strain tensor as well as the rigid body motions.

\section{RECORDING DEVICE}

The variation of the orientation of the incident laser beam and the obtaining of 23 sequential informations during the dynamic event are respectively achieved (Figure 3 and 4) by an acousto-optic deflector and an acousto-optic shutter. The framing rate of this recording device is given by the characteristics of the deflector which allows to record the strain states at a maximum frequency near to $1 \mathrm{MHz}$. The shutter authorises exposure time equal to $30 \mathrm{~ns}$. The optical element, constituted of a multi facets mirror, permits to move each incident beam towards the optical axis in order to illuminate the same measurement point.

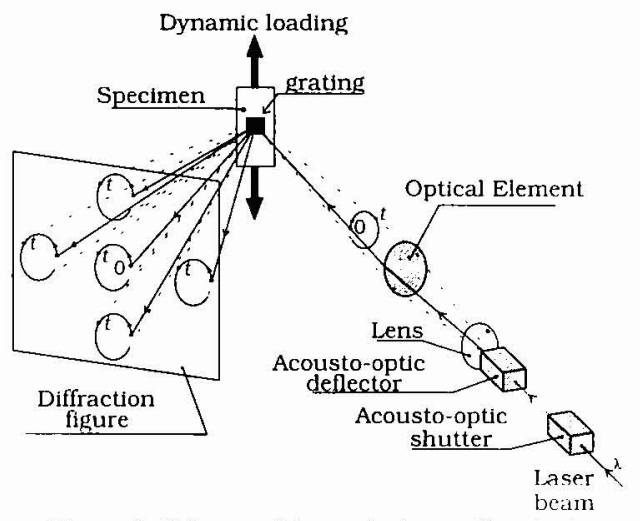

Figure 3: Schema of the optical recording device

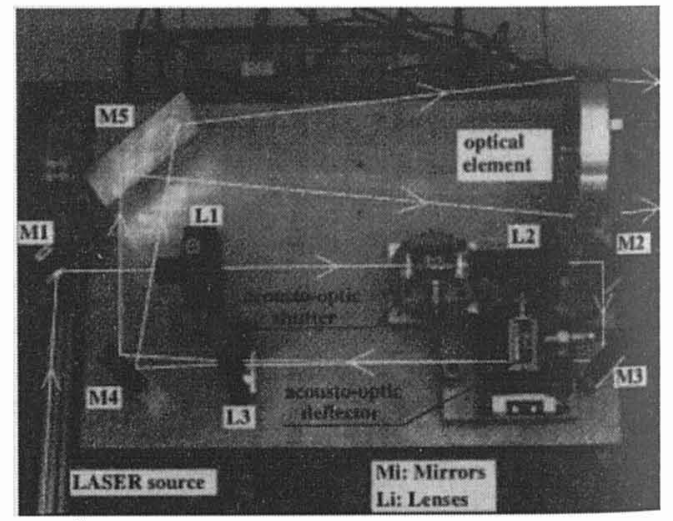

Figure 4: View of the optical recording device 


\section{DATA ANALYSIS}

We give the repartition of the $-1,0$ and +1 diffraction orders for 23 different orientations of the incident beam. The diffraction figure corresponding to the initial state (Figure 5) is compared to the one (Figure 6) associated with an uniform strain increment.

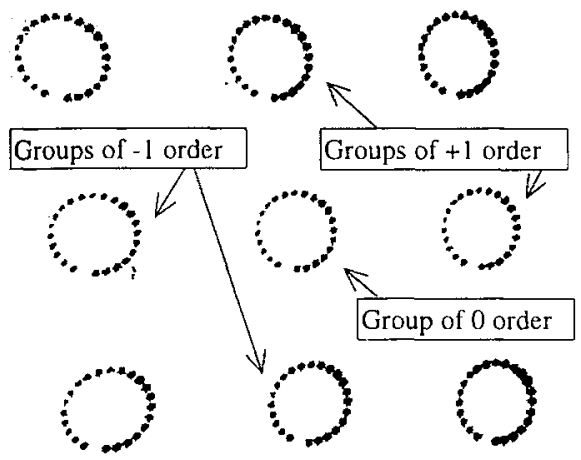

Figure 5: Initial diffraction figure

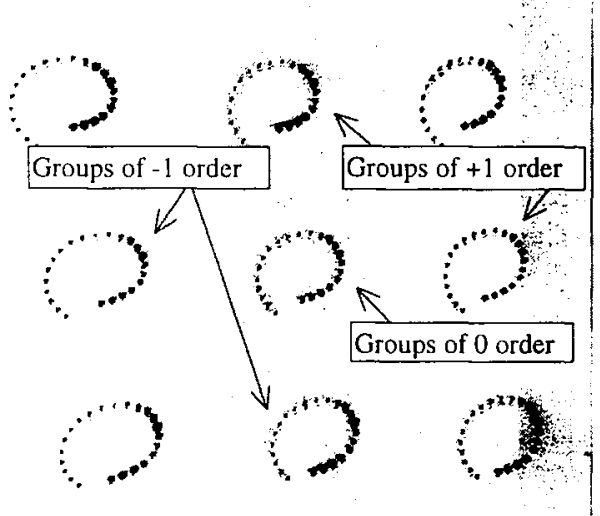

Figure 6: Deformed diffraction figure

These experimental data can be stored on a photographic film or directly on a C.C.D. camera. Some characteristics of the proposed measurement method depend on the chosen storage way.

\subsection{Photographic acquisition}

The diffraction figure is recorded on a photographic film. An adapted analysis device has been developed to determine the position of the 115 spots ( 5 orders of diffraction $\times 23$ states of loading). This device (Figure 7) consists of a XY displacement table for moving the film, and a CCD camera for the acquisition of the spots.

In a first time we create an XY file containing the spots localisation obtained by a global analysis of the film. This analysis is achieved by mounting a photographic lens on the CCD camera and using an appropriate digital image processing. In a second time, we use the XY file to move the film with the motorised displacement table. The diffraction figure is then analysed spot by spot mounting a microscope lens on the CCD camera. By this way, we virtually multiply [8] the number of pixels of the CCD camera (512x 512 pixels to $8000 \times 8000$ pixels with $10 \mu \mathrm{m}$ resolution of the XY displacement) which gives a better localisation of each diffracted spot. This analysis procedure of short duration (about 10 minutes) allows to increase in the same proportion the strain precision of the measurement method.

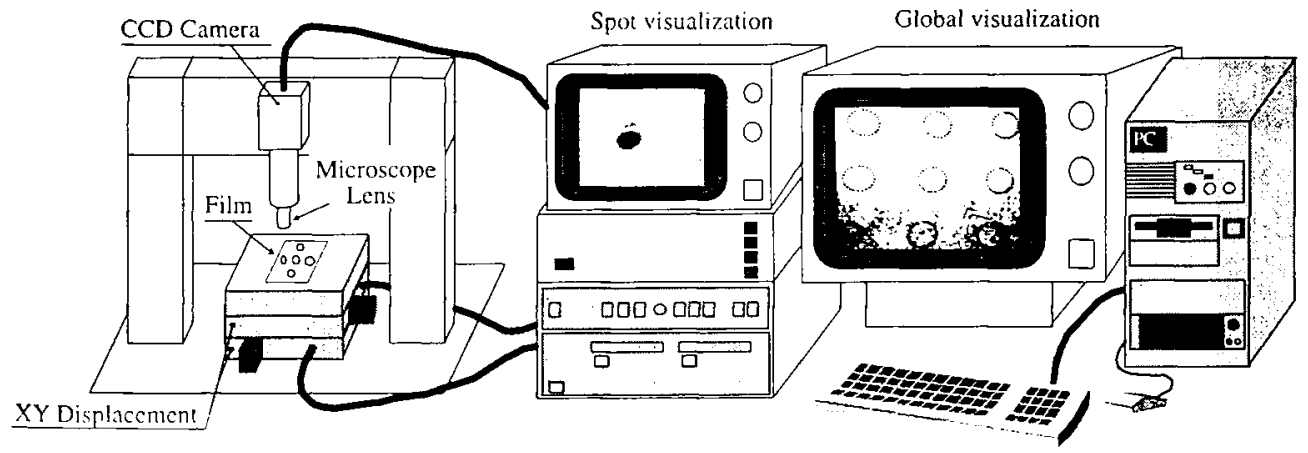

Figure 7: Device of a phomenaphic film and a sis 


\subsection{C.C.D. camera acquisition}

The storage of the diffracted spots is obtained by the synchronisation of the C.C.D. camera acquisition with the dynamic loading (Figure 3). The data analysis is then instantaneous using the appropriate digital image processing in order to localise the centre of the spots.

\subsection{Characteristics}

The strain sensitivity is directly associated to the precision in the determination of the localisation of the diffracted spots. We compare (Figure 8 and 9) the strain sensitivity of the method for the two acquisition ways. The strain sensitivity obtained from a photographic acquisition reaches $2.10^{-4}$ when it is of approximately $3.10^{-3}$ with a C.C.D. camera acquisition. These two quantities are in an equivalent ratio 10 the spatial resolution of the C.C.D. sensor used for the analysis (a virtual sensor with $8000 \times 8000$ pixels for the photographic acquisition, a real sensor with $512 \times 512$ pixels for the camera acquisition). This confirms that the sensitivity is inversely proportional to the number of pixels of the camera used 10 analyse the experimental data.

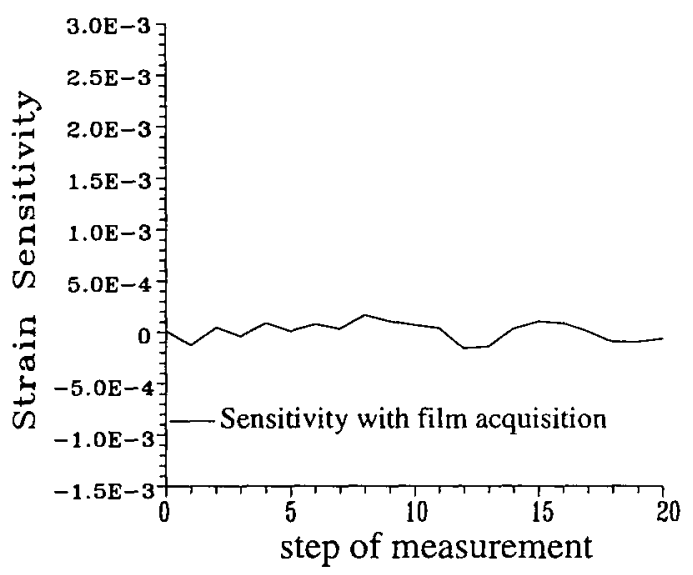

Figure 8: Strain sensitivity with a film acquisition

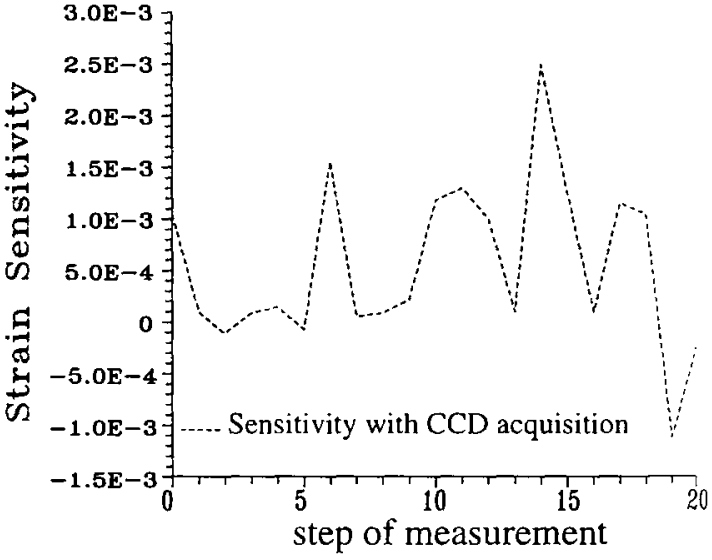

Figure 9: Strain sensitivity with a CCD acquisition

A study of the optical efficiency of the experimental device shows that the use of a recording film of 400 ASA sensitivity with a $50 \mathrm{~mW}$ laser power gives a minimum exposure time equal to $0.5 \mu \mathrm{s}$. The direct recording on a C.C.D. camera $(512 \times 512$ pixels of 8 bits $)$ allows the same experimental conditions. The maximum strain rate permissible depends on the strain sensitivity and on the exposure time. We give (Table 1) these performances for the two acquisition procedures.

Table 1: Strain rate of the method according to the acquisition procedure

\begin{tabular}{|cc|c|c|}
\cline { 2 - 3 } \multicolumn{1}{c|}{} & \multicolumn{1}{c|}{ Film } & \multicolumn{1}{c|}{ Camera } \\
\hline \multicolumn{2}{c|}{ Strain sensitivity } & $2.10^{-4}$ & $3.10^{-3}$ \\
\hline $\begin{array}{c}\text { Exposure } \\
\text { time }\end{array}$ & $0.5 \mu \mathrm{s}$ & $400 \mathrm{~s}^{-1}$ & $6000 \mathrm{~s}^{-1}$ \\
\hline
\end{tabular}




\section{APPLICATIONS}

For all the experimental investigations, the diameter of the measurement base is of about $1 \mathrm{~mm}$. The density of the crossed grating is equal to 200 lines per millimetre.

We present (Figure 10) a compression test using the impact of a mass on the mobile grip of the specimen. The storage of the optical data is realised on a photographic film.. We compare the strain optically measured and those obtained by a classical extensometry using a strain gauge. This is achieved by gluing the bi-directional grating on an uniaxial strain gauge. For this test of $600 \mu \mathrm{s}$, we have chosen the frame rate equal to $35 \mathrm{kHz}$ and an exposure time of $2.8 \mu \mathrm{s}$ ( $10 \%$ of frame rate)

We give (Figure 11) a compression test performing with a Hopkinson bar loading. The incident bar, the transmission bar and the specimen are in aluminium alloy. The projectile speed is equal to $50 \mathrm{~m} / \mathrm{s}$. The acquisition of the optical data is directly achieved with a C.C.D. camera. The frame rate is equal to 500 $\mathrm{kHz}$ with an exposure time equal to $0.2 \mu \mathrm{s}$. The comparison of the longitudinal strain evolution so determined with those given on the incident bar (gage 1) and on the transmission bar (gage 2) shows an identical shape of the evolution with an attenuation of the magnitude during the propagation.

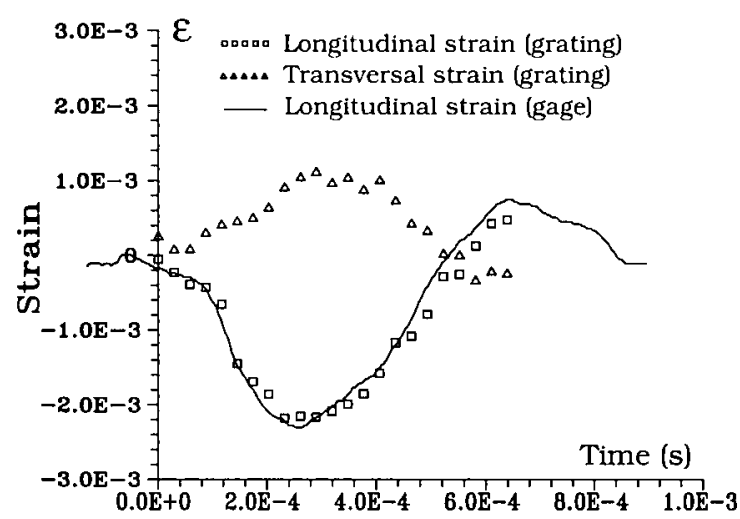

Figure 10: Strains measurement for $0.6 \mathrm{~ms}$ impact duration

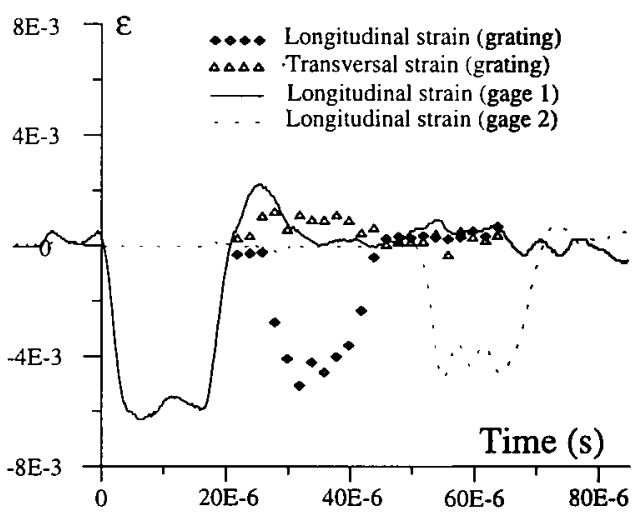

Figure 11: Strains measurement for $20 \mu$ s impact duration

These two dynamic tests give a good idea of the performances of this method. The accordance between longitudinal strains optically determined and classically measured demonstrates the efficiency of the developed method.

\section{CONCLUSION}

The measurement method performed from an interrogation of a crossed grating using the optical diffraction with an oblique incidence allows to determine the strain tensor as well as the six rigid motions of the measurement base.

The use of acousto-optic components allows to separate easily the information during a dynamic or a static loading and to record 24 states of the specimen at up to 1,000,000 frames per second. The small dimensions of the experimental device and the possibility to employ a classical laser source make an attractive experimental tool of this recording set-up .

The storage of the diffraction figure can be achieved by two ways. One utilises the acquisition on a photographic film analysed by specific device composed by a digital image processing using a CCD camera. The other concerns the direct acquisition on CCD camera. The choice of the recording procedure has an influence on some characteristics of the measurement method (strain sensitivity and maximum strain rate). The requirement of a good strain sensitivity involves a storage on a photographic film. when 
the use of the CCD is experimentally easier (the acquisition does not necessitate a total darkness) and authorises an instantaneous analysis of the optical informations.

The performances of the developed method are demonstrated from dynamic tests. On a measurement base of small size, the components of the strain tensor are so optically determined. The accordance with the strains obtained by classical techniques shows the efficiency of the proposed measurement method.

The direct local determination of strains without any contact consitutes a powerful metrology which can help in the study of many dynamic problems (multiaxial loadings, heterogeneous materials). The extending of the presented optical method for a full field measurement must allow a better understanding of some specific dynamic problems (ductile fracture, adiabatic shear bands).

\section{Acknowledgements}

We thank the Search Group GdR "Impact Matériaux" which has financially supported this study.

\section{References}

[1] Sevenhuijsen P.J., "Grid method : a new future", Proceeding of SEM Spring Conference (1989)

[2] Brémand F., Lagarde A.," Analyse spectrale bidimensionnelle d'un réseau de traits croisés. Application à la mesure des grandes et petites déformations", C.R. Académie des Sciences, t. 307, serie ПI (1988i p. 683-688

[3] Brémand F., Dupré J.C., Lagarde A., "Non-contact and non disturbing local strain measurement methods. I - Principle", European Journal of Mechanics, AVSolids, vol 11, n³ (1992) p. 349-366

[4] Cardenas-Garcia J.F., Wu M.S., "Further development of the video optical diffractometer for strain measurement", Proceeding of the SEM Spring Conference (1989)

[5] Dupré J.C., Cottron M., Lagarde A., 1994, "Grating interrogations: from small to large strain measurement", Experimental Mechnics, vol 35, n² (1995) p. 153-158

[6] Bell J. F.,"Determination of dynamic plastic strain through the use of diffraction gratings", Journal of Applied Physics, Vol 27, nº (1956) p. 1109-1113

[7] Valle V., Cottron M., Lagarde A.,"Utilisation du phénomène de diffraction sous incidence oblique d'un faisceau laser par un réseau croisé pour la mesure locale en statique et dynamique des déformations et des mouvements de solide", Mechanics Research Communications, Vol 22, n²/95 (1995) p. 103-107

[8] Valle V., Cottron M., Lagarde A.,"Dynamic optical method for local strain measurements: principle and characteristics", Proceeding of the Euro Dymat 94, Oxford September, C8, Volume 4 (1994) p. $59-64$ 